\title{
Análise da produção normativa no direito à saúde dos inimputáveis - doentes mentais infratores (2011-2014)
}

Analysis of rulemaking on health in the right to health of unindictable mentally ill offenders (2011-2014)

\section{Bárbara Alencar Ávila Borges ${ }^{1}$, Luis Antônio de Moura²}

Resumo: O presente artigo é voltado para o direito à saúde dos doentes mentais que cometeram condutas delitivas. A imputabilidade é a capacidade do agente em entender 0 caráter ilícito do fato praticado e de determinar-se de acordo com isso. Assim, para o doente mental que não pode ser culpável, imputável e penalmente responsabilizado, criouse a medida de segurança. Apesar dos avanços da Reforma Psiquiátrica Brasileira, o direito a um tratamento adequado no SUS está distante de ocorrer, considerando que o 'louco infrator' é sentenciado com medida de segurança para tratamento compulsório em Hospitais de Custódia e Tratamento Psiquiátrico. Avalia-se, então, a abordagem da produção normativa em saúde mental para o cumprimento da política de atenção integral a essa população, tendo em vista que a estratégia para consolidação da política de saúde mental está na legislação do país. Objetiva-se avaliar o direito à saúde dos portadores de doença mental, considerados inimputáveis, na produção normativa vigente no Senado Federal, da Câmara Legislativa e Ministério da Saúde produzida no período de 2011 a 2014. Diante disso, observou-se que, no campo do Direito Sanitário a legislação em saúde mental envolvendo os loucos infratores é pouco estudada e legislada. Diante de vários posicionamentos acerca do tratamento em saúde desses indivíduos, há necessidade de atualização das normativas sobre o tema e a vinculação com o setor de justiça no país. Desde então, discutem-se os obstáculos ao avanço do direito à saúde mental e as possibilidades de sua superação. Por fim, aponta-se a necessidade de fortalecimento de políticas de saúde e de mudanças nas práticas judiciais.

Palavras-chave: Direito Sanitário; Saúde Mental; Inimputabilidade; Produção Normativa.

\begin{abstract}
This article focuses on the right to health of mental patients who have committed criminal conduct. The accountability is the ability of the agent to understand the illicit nature of the fact committed and determined in accordance with it. Thus, for the mentally ill who cannot be guilty, attributable and criminally liable, it was created a safety measure. The study is focused on the right to health of mentally ill persons who have committed criminal behaviors. Despite advances in Brazilian Psychiatric Reform, the right to appropriate treatment in SUS is far from occurring since the "mad offender" is sentenced a detention order for compulsory treatment in hospitals of Custody and Psychiatric Treatment. Then it is evaluated the approach of production rules in mental health for the compliance with the policy is the law of the country. The goal is to assess the right to health of people with

\footnotetext{
${ }^{1}$ Enfermeira. Especializada em Direito Sanitário. Supervisora de Estágio da Universidade Paulista. Técnico de Nível Superior - Enfermeira do Serviço Social do Comércio do Distrito Federal. Brasília, Brasil. E-mail: babi.alencar@hotmail.com

${ }^{2}$ Doutor em Ciência Animal (UFG). Mestre em Ciências da Saúde (UnB). Especialista em Saúde Coletiva (UnB), Vigilância em Saúde Ambiental (UFRJ) e Direito Sanitário (USP). Graduado em Medicina Veterinária (UFG) e Direito (UnB). Atua como Auditor de Atividades Urbanas da Secretaria de Saúde do Distrito Federal (SES/DF). Brasília, Brasil. E-mail: luisam@unb.br
} 
mental illness, considered incompetent, and production in current legislation in the Senate, the Legislative Chamber and the Ministry of Health from 2011 to 2014. Given this, it was observed that, in the field the health Law mental health legislation involving insane offenders is understudied and legislated for. In the face of multiple positions on the health treatment of these individuals, there is a need to update the legislation on the subject and linking with the justice sector in the country. Thereafter, the obstacles to the advancement of the right to mental health and the possibilities of its overcoming have been discussed. Finally, it points out the need for strengthening health policies and of changes in judicial practices.

Keywords: Health Law; Mental Health; Nonimputability; Rulemaking on Health

Resumen: La rendición de cuentas es la capacidad del agente de comprender el carácter ilícito del hecho cometido y determinado de acuerdo con él. Por lo tanto, para los enfermos mentales que no pueden ser culpables, atribuible penalmente responsable, fue elaborado una medida de seguridad. El estudio se centra en el derecho a la salud de las personas con enfermedades mentales que han cometido conductas delictivas. A pesar de los avances de la Reforma Psiquiátrica Brasileña, el derecho a un tratamiento adecuado en el Sistema Único de Salud (SUS) está lejos de ser ocurriendo desde que el "delincuente loco" es a medida de seguridad condenados por el tratamiento obligatorio en los hospitales de Custodia y Tratamiento Psiquiátrico. Evalúa entonces, el enfoque de las normas de producción en salud mental para el cumplimiento de la atención política plena a esta población, ya que la estrategia para la consolidación de la política de salud mental es la ley del país. El objetivo es evaluar el derecho a la salud de las personas con enfermedad mental en las actuales reglas de producción en el Senado, la Cámara Legislativa y el Ministerio de Salud producido en el período 2011-2014. De este modo, se observó que, en el campo la Ley de Salud legislación de salud mental que involucra delincuentes loco está poco estudiado y legislado. A través de varias posiciones en la salud de estas personas en el tratamiento, sin necesidad de actualizar la normativa sobre la materia y la vinculación con el sector de la justicia en el país. A partir de entonces, se discuten los obstáculos para el avance del derecho a la salud mental y las posibilidades de superarlos. Por último, apunta a la necesidad de fortalecer las políticas de salud y los cambios en las prácticas judiciales.

Palabras-Ilave: Derecho Sanitario; Salud Mental; Inimputabilidad; Producción Normativa.

\section{Introdução}

A imputabilidade é entendida como a capacidade do agente em entender o caráter ilícito do fato praticado e de determinar-se de acordo com ele. Essa capacidade está relacionada à existência de fatores biológicos (maioridade penal), psiquiátricos (sanidade mental), psicológicos (discernimento pleno e voluntariedade) e até antropológicos (entendimento dos padrões socioculturais que predominam num meio social determinado). Além da consciência de sua ação, faz-se necessária a vontade de praticá-la, ou seja, o controle do agente sobre a sua própria vontade (MALCHER, 2009). 
Conforme o artigo 26 do Código Penal Brasileiro (CPB, 1940):

É isento de pena o agente que, por doença mental ou desenvolvimento mental incompleto ou retardado, era, ao tempo da ação ou da omissão, inteiramente incapaz de entender o caráter ilícito do fato ou de determinar-se de acordo com esse entendimento (BRASIL, 1940).

A simples existência de doença mental do indivíduo avaliada somente por sintomas não é reconhecida como inimputabilidade e nem atinge a capacidade de percepção do autor (COHEN, 1996; VAZ, 2012). Entretanto, hoje, o inimputável que cometer delito se sujeita apenas à medida de segurança, pois a partir da Reforma Penal de 1984 os inimputáveis são isentos de pena (BITENCOURT, 2004).

Assim, para o doente mental que não pode ser culpável, imputável e penalmente responsabilizado, criou-se a medida de segurança. No art. 76 do CPB, a aplicação da medida de segurança pressupõe a prática do fato previsto como crime e a periculosidade do agente (BRASIL, 1940). Diferente das penas que possuem caráter retributivo-preventivo e são determinadas, a medida de segurança é uma intervenção meramente preventiva e têm tempo indeterminado para os inimputáveis, neste caso, portadores de doença mental crônica ou provisória (BITENCOURT, 2004).

A periculosidade do agente pode ser conceituada como 'um estado subjetivo mais ou menos duradouro de anti-sociabilidade' (BITENCOURT, 2004). No art. 77 do Código Penal Brasileiro, quando a periculosidade não é presumida por lei, deve ser reconhecido perigoso o indivíduo, se a sua personalidade e antecedentes, bem como os motivos e circunstâncias do crime autorizam a suposição que venha ou torne a delinquir (BRASIL, 1940).

O princípio do ne bis in idem é lesado na aplicação aliada de pena e medida de segurança. A medida de segurança acaba por encontrar justificativa somente na periculosidade conjunta à incapacidade penal do agente. Antigamente, a pena privativa de liberdade, praticamente não se distinguia da medida de segurança, já que era retirado do indivíduo o seu direito de liberdade. A pena era certa e determinada, porém o indivíduo cumpria outra pena incerta sendo denominada medida de segurança (BITENCOURT, 2004).

Vale salientar que a pena aplicada será correspondente à infração penal realizada, no caso da necessidade do infrator de um 'especial tratamento curativo' aplicará a medida de segurança (BITENCOURT, 2004). 
Falconi (1998) conceitua a medida de segurança:

É uma decisão judicial que substitui a pena convencional por tratamento de saúde ao imputado que sofre, ou venha a sofrer, de qualquer distúrbio mental, amparando-o com o não apenamento convencional, que somente é permitido aos mentalmente sãos.

Não há condenação ao inimputável, ao contrário, é feita absolvição e, consequentemente, aplicada a medida de segurança; dessa forma, a duração da privação de liberdade fica indeterminada. Gomes (1993; apud BITENCOURT, 2004) afirma ser a medida de segurança uma inconstitucional prisão perpétua, e indica que seu limite não deve ser maior que o limite máximo da pena delegada ao delito praticado.

Desse modo, as medidas de segurança vêm para suprir a falta de pena para os doentes mentais. No caso, as penas geram um novo olhar na defesa da sociedade envolvida na prevenção e deveria ser determinada pela periculosidade da pessoa (CORREIA; LIMA; ALVES, 2007).

A eliminação da periculosidade do agente é o objetivo da medida de segurança, prestando um cuidado apropriado à saúde mental, de modo que seja tratado e não reincida, protegendo a si próprio e a sociedade. Teoricamente, esses indivíduos estão resguardados pelo CPB, no qual é prevista avaliação médica, e pela Lei 10.216, de 06 de abril de 2001, que trata da Reforma Psiquiátrica, e elenca os direitos fundamentais dessas pessoas (CREMESP, 2013).

Se o agente for inimputável, o juiz determinará sua internação, conforme art. 26 do CPB. Embora, se o fato previsto como crime for punível com detenção, poderá o juiz submetê-lo a tratamento ambulatorial. Observa-se que a medida de segurança é indeterminada até que cesse a periculosidade do agente, verificada por perícia médica, conforme 0 art. $97 \S 1^{\circ}$, do CPB.

Na verificação da cessação de periculosidade, a Lei 7.210, de 11 de julho de 1984, conhecida como Lei de Execução Penal (LEP), garante o direito de contratar um médico, a critério da família ou do paciente, no acompanhamento do tratamento. Na hipótese de haver diferentes opiniões entre o médico oficial e o escolhido pela família, o juiz resolverá o caso (BRASIL, 1984). Bitencourt (2004) acredita que o médico particular, sendo assistente técnico, tem direito à participação na realização do exame de verificação de cessação de periculosidade, baseado no princípio da ampla defesa descrito no art. 5ำ, IV, da Constituição Federal Brasileira (BRASIL, 1988). 
Ainda que seja determinada a cessação da medida ficará subjugada por uma condição resolutiva pelo prazo de um ano. Nesse prazo, se a pessoa praticar algum ato indicativo de periculosidade, mesmo não sendo ilícito penal, a medida de segurança estabelecida poderá ser aplicada novamente. O Ministério Público, em tal ocasião, sem haver outro órgão indicado por lei, toma providências a fim de reestabelecer a medida e submeter o indivíduo a novos exames (MARCÃO, 2008).

Diante disso, o Departamento Penitenciário Nacional (DPN), responsável pela execução da Política Criminal e Penitenciária do país, alia-se à Área Técnica de Saúde Mental do Ministério da Saúde (MS), aos responsáveis pela custódia dos loucos infratores, na construção de programas permanentes de reintegração social desses pacientes. $O$ fato é que os loucos infratores não devem ser excluídos dos programas de saúde que integram o Programa Nacional de Saúde para o Sistema Penitenciário (MALCHER, 2009; VAZ, 2012).

O CPB prevê duas espécies de medida de segurança. A primeira é a internação em Hospitais de Custódia e Tratamento Psiquiátrico (HCTP), também conhecida como medida de detenção, que na ausência de tais hospitais pode ser cumprida em outro estabelecimento adequado. Segundo Bitencourt (2004), como nenhum estado brasileiro construiu lugares novos, o novo termo adotado pela Reforma não alterou as condições dos manicômios judiciários.

A segunda espécie é o tratamento ambulatorial, no caso de delitos de menor gravidade. Neste caso não há internação, apenas cuidados de saúde, prestados ao indivíduo. É imprescindível avaliar os condicionantes pessoais do agente, a fim de verificar se este é compatível ou não com a medida mais liberal, pois se forem favoráveis impõe-se a substituição. A qualquer tempo pode haver determinação do juiz para a internação do agente, desde que seja fundamental para fins terapêuticos (BITENCOURT, 2004; GRECO, 2007; MARCÃO, 2008).

As internações são realizadas nos HCTP, os chamados manicômios judiciários. Ao contrário disso, a internação, se necessária, deve ser realizada na rede de atenção psicossocial do Sistema Único de Saúde (SUS). Os Centros de Atenção Psicossocial (CAPS), unidades de atendimento aos portadores de transtorno mental, constituem uma alternativa ao modelo centrado no hospital psiquiátrico e permitem que os usuários permaneçam junto à sua família e comunidade. Os CAPS fazem parte da rede e estão 
direcionados à assistência dos portadores de doença mental (DINIZ, 2011; MATEUS, 2013).

As residências terapêuticas constituem-se como alternativas de moradia para um grande contingente de pessoas que estão internadas há anos em hospitais psiquiátricos, por não contarem com suporte adequado na comunidade. O Serviço Residencial Terapêutico (SRT), também conhecido como residência terapêutica ou simplesmente moradia, é formado por casas localizadas no espaço urbano, construídas para responder às necessidades de moradia de pessoas portadoras de transtornos mentais graves, institucionalizadas ou não. Elas servem de apoio aos usuários de outros serviços de saúde mental, que não contam com suporte familiar e social suficientes para garantir espaço adequado de moradia (MATEUS, 2013).

O Parecer sobre medidas de segurança e HCTP sob a perspectiva da Lei no 10.216/2001, realizado pelo Ministério Público Federal (MPF), Procuradoria Federal dos Direitos do Cidadão (PFDC), em 2011, traz fatos que levam a repensar a assistência ao paciente com transtorno mental. $\mathrm{O}$ documento mostra ambiguidades, como a ação de médicos versus juízes, já que cada um dispõe de uma determinada formação acadêmica e porque a relação entre a saúde e a lei cai em conflito. O direito à saúde dos inimputáveis é negado até mesmo na medida de segurança outorgada pelo juiz (BRASIL, 2011).

Observado então o devido processo legal aplicado pelo juiz, a medida de segurança deve ser cumprida em um HCTP, sendo que o objetivo da internação é exclusivamente o tratamento psiquiátrico do indivíduo. O caráter preventivo da medida de segurança constitui em um processo terapêutico para tornar o quadro patológico estável. Bem como, criticam Correia e colaboradores (2007), a medida de segurança torna-se para o interno uma ausência da perspectiva de convívio com a sociedade.

Os HCTP têm sua população composta por sujeitos que enfrentam uma situação de vulnerabilidade considerável no meio social. Estes resistiram até mesmo à Reforma Psiquiátrica, pois continuaram sendo inaugurados após a Lei 10.216/2001, que regulamenta o direito e a proteção das pessoas acometidas de transtornos mentais. $O$ direito à saúde mencionado na normativa não se torna evidenciado nessas instituições, existindo, inclusive pessoas internadas que ultrapassaram a medida de segurança e ainda alguns se consideram acima do tempo de regime dos imputáveis, ou seja, há mais de 30 anos (DINIZ, 2013). 
Atualmente, os HCTP são mais parecidos com presídios do que com hospitais e são geridos pelo Sistema Judiciário, não pelo SUS. O que por sua vez, gera um viés no direito sanitário dos portadores de doença mental que cometeram delitos. Assim, discute-se a atuação do SUS na implementação da atenção à saúde desses usuários, já sendo executado segundo o Plano Nacional de Saúde ao Sistema Penitenciário e na Política de Saúde Mental. O plano está focalizado na prevenção e promoção da saúde dos indivíduos. Salienta-se, neste fato, o princípio da universalidade no SUS (CREMESP, 2013).

O Censo de 2011 demonstra que, nos HCTP, a população é em sua maioria formada por pardos e negros (44\%), com baixo nível de escolaridade, sendo $23 \%$ de analfabetos e 43\% com nível fundamental incompleto, e que exerciam profissões que exigem pouca qualificação técnica. O documento registra que há enormes violações dos direitos. Aproximadamente $70 \%$ dos internos que estavam em medida de segurança poderiam ser considerados réus primários. O atraso na realização anual do exame de cessação de periculosidade é de $41 \%$, com destaque para um indivíduo que estava internado há 32 anos por tentativa de furto (DINIZ, 2013).

Avalia-se, então, a abordagem da legislação em saúde mental para o cumprimento da política de atenção integral à essa população, já que a estratégia para consolidação da política de saúde mental está na legislação do país. Os direitos dos portadores de saúde mental que cometeram delito devem ser defendidos com o propósito de reduzir a discriminação e a marginalização. Além disso, as normas regulam o sistema de atendimento em saúde mental, e com a regulamentação dessas ações e a implementação da política voltada aos delinquentes ficam embasadas na normatização do SUS (BERTOLOTE, 1995; MATEUS, 2013).

Diante do exposto, o seguinte questionamento pode ser feito: como é tratado na legislação vigente o direito à saúde dos inimputáveis portadores de transtorno mental que cometeram delitos? Salienta-se que existe uma deficiência na legislação em saúde mental aplicada à essa população esquecida.

Assim, o objetivo geral é avaliar o direito à saúde dos portadores de doença mental, considerados inimputáveis, na produção normativa vigente produzida no período de 2011 a 2014, no âmbito federal. Como objetivo específico, destaca-se a pesquisa do direito à saúde dos inimputáveis na legislação vigente no período mencionado, envolvendo a produção normativa do Congresso Nacional Brasileiro, Presidência da República e 
Ministérios da Saúde e da Justiça, realizando um levantamento das legislações abarcando a condição dos doentes mentais e as medidas de segurança.

\section{Metodologia}

Foi realizada pesquisa documental, a partir do Portal de Legislação disponível nos sítios do Congresso Nacional Brasileiro e do Ministério da Saúde (SaudeLegis) e, ainda, de artigos científicos nas bases Scielo, BVS e Google acadêmico. A análise de conteúdo das legislações foi obtida por meio dos achados. Os descritores utilizados na coleta de dados foram: Inimputáveis, Direito à Saúde, Saúde Mental, Delito.

A pesquisa é qualitativa, pois utilizou análise de conteúdo dos textos na busca do envolvimento com o sistema prisional e a medida de segurança dos doentes mentais considerados inimputáveis. A análise é estabelecida a partir do direito à saúde do doente mental que cometeu algum delito e, verifica os avanços dessas normas. Como critério de inclusão, privilegiaram-se as leis federais, decretos e portarias.

O período dos documentos selecionados para a pesquisa foi de janeiro de 2011 ao primeiro semestre de 2014. O marco inicial foi o ano de 2011, devido ao Parecer do Ministério Público do Distrito Federal e Territórios sobre Medidas de Segurança e Hospitais de Custódia e Tratamento Psiquiátrico, sob a perspectiva da Lei no 10.216/2001. Além disso, a Coletânea de Legislação em Saúde Mental (2004-2010), elaborada pelo Ministério da Saúde, é composta de normas até o ano de 2010. A coleta de dados ocorreu de agosto de 2014 a setembro de 2014.

\section{Discussão}

A partir da busca da produção normativa no portal do Senado Federal, da Câmara Legislativa e Ministério da Saúde, observou-se que, no campo do Direito Sanitário, a legislação em saúde mental envolvendo os loucos infratores é pouco estudada e legislada. Apesar da Lei no 10.216, de 2001, tratar de vários posicionamentos acerca do tratamento em saúde desses indivíduos, há necessidade de atualização da legislação acerca do tema e a vinculação com o setor de justiça no país.

Ao todo, foram encontradas 14 normas públicas, de 2011 a 2014, sobre a temática da saúde mental relacionadas aos inimputáveis, sendo um Decreto Presidencial, onze 
Portarias do Ministério da Saúde, uma Portaria Interministerial do Ministério da Saúde e do Ministério da Justiça, e uma Lei Complementar (QUADRO 1).

Quadro 1 - Produção Normativa sobre Direito à Saúde dos Doentes Mentais em leis federais, decretos e portarias. Brasil, 2011-2014.

\begin{tabular}{|c|c|c|c|}
\hline Normativa & Data & Órgão & Conteúdo \\
\hline Decreto nº 7.508 & $28 / 06 / 2011$ & $\begin{array}{l}\text { Presidência da } \\
\text { República }\end{array}$ & $\begin{array}{l}\text { Regulamenta a Lei } \mathrm{n}^{\circ} 8.080 \text {, de } 19 \text { de } \\
\text { setembro de } 1990 \text {, para dispor sobre a } \\
\text { organização do Sistema Único de Saúde - } \\
\text { SUS, o planejamento da saúde, a } \\
\text { assistência à saúde e a articulação } \\
\text { interfederativa, e dá outras providências. }\end{array}$ \\
\hline Portaria n-2.488 & $21 / 10 / 2011$ & $\begin{array}{l}\text { Ministério } \\
\text { Saúde }\end{array}$ & $\begin{array}{l}\text { Aprova a Política Nacional de Atenção } \\
\text { Básica (PNAB), estabelecendo a revisão de } \\
\text { diretrizes e normas para a organização da } \\
\text { Atenção Básica, para a Estratégia Saúde da } \\
\text { Família (ESF) e o Programa de Agentes } \\
\text { Comunitários de Saúde (PACS). }\end{array}$ \\
\hline Portaria nº 3.088 & $23 / 12 / 2011$ & $\begin{array}{ll}\text { Ministério } & \text { da } \\
\text { Saúde } & \end{array}$ & $\begin{array}{l}\text { Institui a Rede de Atenção Psicossocial para } \\
\text { pessoas com sofrimento ou transtorno } \\
\text { mental e com necessidades decorrentes do } \\
\text { uso de crack, álcool e outras drogas, no } \\
\text { âmbito do Sistema Único de Saúde (SUS). } \\
\text { Brasília, 2011. }\end{array}$ \\
\hline Portaria $n^{0} 121$ & $25 / 01 / 2012$ & $\begin{array}{ll}\text { Ministério } & \text { da } \\
\text { Saúde } & \end{array}$ & $\begin{array}{l}\text { Institui a Unidade de Acolhimento para } \\
\text { pessoas com necessidades decorrentes do } \\
\text { uso de Crack, Álcool e Outras Drogas } \\
\text { (Unidade de Acolhimento), no componente } \\
\text { de atenção residencial de caráter transitório } \\
\text { da Rede de Atenção Psicossocial. }\end{array}$ \\
\hline Portaria no 148 & $31 / 01 / 2012$ & $\begin{array}{l}\text { Ministério } \\
\text { Saúde }\end{array}$ & $\begin{array}{l}\text { Define as normas de funcionamento e } \\
\text { habilitação do Serviço Hospitalar de } \\
\text { Referência para atenção a pessoas com } \\
\text { sofrimento ou transtorno mental e com } \\
\text { necessidades de saúde decorrentes do uso } \\
\text { de álcool, crack e outras drogas, do } \\
\text { Componente Hospitalar da Rede de Atenção } \\
\text { Psicossocial, e institui incentivos financeiros } \\
\text { de investimento e de custeio. }\end{array}$ \\
\hline Portaria no 349 & 29/02/2012 & $\begin{array}{l}\text { Ministério } \\
\text { Saúde }\end{array}$ & $\begin{array}{l}\text { Altera e acresce dispositivo à Portaria } \mathrm{n}^{\circ} \\
\text { 148/GM/MS, de } 31 \text { de janeiro de } 2012 \text {, que } \\
\text { define as normas de funcionamento e } \\
\text { habilitação do Serviço Hospitalar de } \\
\text { Referência para atenção a pessoas com } \\
\text { sofrimento ou transtorno mental e com } \\
\text { necessidades decorrentes do uso de crack, } \\
\text { álcool e outras drogas, do Componente } \\
\text { Hospitalar da Rede de Atenção Psicossocial } \\
\text { e institui incentivos financeiros de } \\
\text { investimento e de custeio }\end{array}$ \\
\hline
\end{tabular}


Cad. Ibero-Amer. Dir. Sanit., Brasília, v.4, n.2, abr/jun. 2015 ISSN 2358-1824

\begin{tabular}{|c|c|c|c|}
\hline Normativa & Data & Órgão & Conteúdo \\
\hline Portaria no 854 & $22 / 08 / 2012$ & $\begin{array}{l}\text { Ministério da } \\
\text { Saúde }\end{array}$ & $\begin{array}{l}\text { Altera a Tabela de Procedimentos, } \\
\text { Medicamentos, Órteses, Próteses e } \\
\text { Materiais Especiais do Sistema Único de } \\
\text { Saúde os seguintes atributos dos } \\
\text { procedimentos a seguir especificados, a } \\
\text { partir da competência Outubro de 2012. }\end{array}$ \\
\hline Portaria $\mathrm{n}^{0} 855$ & $22 / 08 / 2012$ & $\begin{array}{l}\text { Ministério } \quad \text { da } \\
\text { Saúde }\end{array}$ & $\begin{array}{l}\text { Inclui na Tabela de Incentivos das Redes do } \\
\text { SCNES os incentivos. }\end{array}$ \\
\hline Portaria no 856 & $22 / 08 / 2012$ & $\begin{array}{l}\text { Ministério } \quad \text { da } \\
\text { Saúde }\end{array}$ & $\begin{array}{l}\text { Definir mecanismos para operacionalização } \\
\text { dos procedimentos específicos para a } \\
\text { atenção residencial de caráter transitória às } \\
\text { pessoas com necessidades decorrentes do } \\
\text { uso de álcool, crack e outras drogas, } \\
\text { realizados em serviços de atenção em } \\
\text { regime residencial. }\end{array}$ \\
\hline Lei $n^{0} 12.714$ & $14 / 09 / 2012$ & $\begin{array}{l}\text { Presidência da } \\
\text { República }\end{array}$ & $\begin{array}{l}\text { Dispõe sobre } \\
\text { acompanhamento da execução das penas, } \\
\text { da prisão cautelar e da medida de } \\
\text { segurança. }\end{array}$ \\
\hline Portaria $n^{0} 1.218$ & $26 / 10 / 2012$ & $\begin{array}{l}\text { Ministério da } \\
\text { Saúde }\end{array}$ & $\begin{array}{l}\text { Altera a redação da Portaria no } 854 / \text { SAS/MS, } \\
\text { de } 22 \text { de agosto de } 2012 \text {. }\end{array}$ \\
\hline $\begin{array}{l}\text { Portaria Interministerial } \\
\mathrm{n} 01\end{array}$ & $02 / 01 / 2014$ & $\begin{array}{l}\text { Ministério da } \\
\text { Saúde e } \\
\text { Ministério da } \\
\text { Justiça }\end{array}$ & $\begin{array}{l}\text { Institui a Política Nacional de Atenção } \\
\text { Integral à Saúde das Pessoas Privadas de } \\
\text { Liberdade no Sistema Prisional (PNAISP) no } \\
\text { âmbito do Sistema Único de Saúde (SUS). }\end{array}$ \\
\hline Portaria no 94 & $14 / 01 / 2014$ & $\begin{array}{l}\text { Ministério } \\
\text { Saúde }\end{array}$ & $\begin{array}{l}\text { Institui o serviço de avaliação e } \\
\text { acompanhamento de medidas terapêuticas } \\
\text { aplicáveis à pessoa com transtorno mental } \\
\text { em conflito com a Lei, no âmbito do Sistema } \\
\text { Único de Saúde (SUS). }\end{array}$ \\
\hline Portaria $n^{0} 482$ & $01 / 04 / 2014$ & $\begin{array}{l}\text { Ministério } \\
\text { Saúde }\end{array}$ & $\begin{array}{l}\text { Institui normas para a operacionalização da } \\
\text { Política Nacional de Atenção Integral à } \\
\text { Saúde das Pessoas Privadas de Liberdade } \\
\text { no Sistema Prisional (PNAISP) no âmbito do } \\
\text { Sistema Único de Saúde (SUS). }\end{array}$ \\
\hline
\end{tabular}

Fonte: Congresso Nacional Brasileiro e Ministério da Saúde, 2014.

Apesar de não ser considerado uma norma, o Parecer sobre Medidas de Segurança e Hospitais de Custódia e Tratamento Psiquiátrico sob a perspectiva da Lei 10.216/2001 do MPF é um documento de suma importância para o campo da saúde mental, por envolver o Direito Sanitário, considerando que trata das situações contraditórias presentes na legislação de saúde mental. Propõe a aplicação dos princípios da CF/1988 na perspectiva do SUS, na qual a pessoa com transtorno mental deve ter o seu tratamento não restrito a HCTP e, sim, na Rede de Atenção Básica do SUS. Considera, ainda, a referida Lei um marco para a fundamentação dos direitos das pessoas com transtornos mentais, no que 
concerne ao estabelecimento da necessidade do respeito à dignidade humana, independente de sua condição de saúde (BRASIL, 2011a).

O portador de doença mental é tratado no documento, desde a nomenclatura usada para seu chamamento, como qualquer outra pessoa que deve ter seus direitos garantidos de formal integral. São propostas medidas, como a criação de programas estaduais de assistência a pessoas com transtornos mentais e a extinção dos HCTP, o que na realidade é uma estratégia tratada há muito, porém não é realizada em diversos estados e municípios brasileiros (BRASIL, 2011a).

A Lei 10.216/2001 inclui os portadores de transtornos mentais autores de delitos; pois, trata dos direitos e da proteção assegurados, sem nenhuma forma de discriminação. Desde então, todas as normas de saúde mental devem ser aplicadas aos internos de manicômios judiciários e de hospitais psiquiátricos que cometeram algum delito tipificado como crime na lei penal (BRASIL, 2001; JACOBINA 2008).

É fato que a pessoa acometida de transtorno mental a qual é imposta a medida de segurança deva ser levada a tratamento ambulatorial ou internação, pleiteando sua melhora; entretanto, existem falhas nos ambulatórios, e nas internações os pacientes são submetidos a longos períodos de prisão comum, aguardando vaga em HCTP. A situação ainda encontrada no país é caótica e tem gerado constrangimento ilegal (MARCÃO, 2008).

O Decreto 7.508, de 28 de junho de 2011, trata de alterações na Lei 8.080, de 19 de setembro de 1990, conhecida como Lei Orgânica da Saúde, com o intuito de regulamentar questões fundamentais, mostrando-se como um passo importante rumo à consolidação e à

real operacionalização do SUS. Verifica-se que o Decreto deu continuidade à ênfase na regionalização prevista constitucionalmente, já tratada nas normas operacionais do SUS. A atenção psicossocial é tratada neste documento como pertencente à Rede de Saúde bem como porta de entrada do serviço, evidenciando o direito à saúde mental. Ainda reforça os princípios e diretrizes do SUS, mas também do acesso universal, igualitário e ordenado nas ações e serviços (BRASIL, 2011b).

O atendimento ao usuário de álcool, crack e outras drogas também é abordado nas normas do período pesquisado. Os usuários de álcool, crack e outras drogas têm garantia de acesso e da qualidade dos serviços de saúde mental na Rede de Atenção Psicossocial. Seu amparo legal está constituído na Portaria n 3.088-GM/MS, de 23 de dezembro de 2011, na Portaria n 148-GM/MS, de 31 de janeiro de 2012 e é alterada a redação na 
Portaria ํㅡㄴ 349-MS de 29 de fevereiro de 2012 (BRASIL, 2011d; BRASIL, 2012b; BRASIL, 2012c).

Salienta-se que, pela leitura da Portaria no 2.488-GM/MS, de 21 de outubro de 2011, que aprova a Política Nacional de Atenção Básica (PNAB), e estabelece a revisão de diretrizes e normas para a organização da Atenção Básica, para a Estratégia Saúde da Família (ESF) e o Programa de Agentes Comunitários de Saúde (PACS), o portador de saúde mental que cometeu delito deve ser respaldado na Atenção Básica, pois o sistema deve ser integral e universal a todos os indivíduos de forma equânime (BRASIL, 2011c).

$\mathrm{Na}$ Portaria no 3.088-MS, de 23 de dezembro de 2011, são apresentadas as diretrizes para o funcionamento da Rede de Atenção Psicossocial, bem como a criação e ampliação de centros de atenção. Aborda, ainda, os serviços residenciais terapêuticos como estratégia de desinstitucionalização, sendo o foco de atenção à saúde mental dos indivíduos portadores de transtorno mental (BRASIL, 2011d).

A Portaria 854-MS, de 22 de agosto de 2012, altera e cria os novos procedimentos adotados pelos CAPS, com a finalidade de qualificar o processamento e o monitoramento da produção no sistema de informação em saúde. Refere-se, especificamente, às ações que fazem parte do processo de trabalho das equipes dos CAPS, permitindo melhor acompanhar o modelo de atenção vigente nestes serviços. A importância da norma, apesar de não estar diretamente vinculada ao paciente mental que cometeu delito, está na atenção à saúde mental desse indivíduo (BRASIL, 2012d).

As Portarias 855/MS e 856/MS, ambas de 22 de agosto de 2012, também descrevem a atenção à saúde de caráter residencial às pessoas com transtornos mentais decorrentes do uso de crack, álcool e outras drogas. A primeira trata da inclusão da Tabela de Incentivos das Redes do Sistema de Cadastro Nacional de Estabelecimentos de Saúde (SCNES) dos CAPS para operacionalizar os procedimentos específicos para a atenção de caráter residencial às pessoas com transtornos mentais decorrentes do uso de drogas. Já a segunda, refere-se à inclusão da tabela de incentivos do SCNES. A Portaria ํㅜ 1.218 MS, de 12 de outubro de 2012, apenas altera a redação da Portaria 854-MS, de 2012 (BRASIL, 2012e; BRASIL, 2012f).

Em face do quadro alarmante que é o cumprimento da medida de segurança por parte dos inimputáveis, a Lei 12.714, de 14 de setembro de 2012, vem trazer transparência às ações desenvolvidas. A norma dispõe sobre o sistema de acompanhamento da 
execução das penas, da prisão cautelar e da medida de segurança, estabelecendo que um sistema informatizado fará com que os dados e as informações acerca de seu cumprimento pelos inimputáveis possam ser verificadas, facilitando o processo de reavaliação da conduta aplicada ao indivíduo (BRASIL, 2012g).

Há um intervalo de ausência de leis vinculadas ao portador de saúde mental que comete conduta delitiva, observada no ano de 2013. Em 2014, a Política Nacional de Atenção Integral a Saúde das Pessoas Privadas de Liberdade no Sistema Prisional (PNAISP), instituída pela Portaria Interministerial no 1 MS/MJ, de 2 de janeiro de 2014, no âmbito do SUS, define como pessoas privadas de liberdade no sistema prisional aquelas com idade superior a 18 (dezoito) anos e que estejam sob a custódia do Estado em caráter provisório ou sentenciados, para cumprimento de pena privativa de liberdade ou medida de segurança, conforme previsto no Decreto-Lei 3.689, de 3 de outubro de 1941 (Código de Processo Penal) e na LEP. Sendo a norma mais importante nos últimos anos que revalida o direito à saúde dos inimputáveis doentes mentais (BRASIL, 2014a).

Mesmo no art. 59 das Regras Mínimas para o Tratamento do Preso no Brasil, Resolução 14 do Conselho Nacional de Política Criminal e Penitenciária (CNPCP), de 1994, é prevista ao doente mental a custódia realizada em estabelecimento apropriado, não podendo permanecer em prisão passado o tempo preciso para sua transferência (BRASIL, 1994). Segundo Marcão (2008), é inadmissível a permanência do doente mental em regime fechado, constituindo constrangimento ilegal, por ausência de vagas em hospital apropriado.

Essa visão justifica a inserção não somente do doente mental, mas também do preso comum ao atendimento no SUS. Os CAPS realizam o atendimento em nível ambulatorial e em consonância com a lei, de forma a inserir a família destes indivíduos nos programas. As residências terapêuticas visam os sujeitos sem família, além do apoio de assistência social.

A Portaria 94-MS, de 14 de janeiro de 2014, institui a avaliação e acompanhamento de medidas terapêuticas aplicáveis à pessoa com transtorno mental em conflito com a Lei, no âmbito do SUS. Vinculado à PNAISP, esse documento demonstra avanços no direito dos doentes mentais. Como suscita o Parecer supramencionado e demais leis anteriores, esta Portaria direciona as ações da política e as atribuições são delegadas como o acompanhamento da execução da medida terapêutica. A intersetorialidade tão discutida é 
tratada como garantidora da atuante interlocução entre os órgãos de Justiça, as equipes da PNAISP, de programas e serviços sociais e de direitos de cidadania. O interesse maior é a oferta de acompanhamento integral, resolutivo e contínuo (BRASIL, 2014b).

$\mathrm{Na}$ Portaria 482, de $1^{\circ}$ de abril de 2014, são tratadas as normas para a operacionalização da PNAISP. A estruturação das equipes de saúde mental é devidamente abordada no documento. Inclusive, recomenda a habilitação da equipe de saúde e caracteriza a assistência preferencial às pessoas privadas de liberdade com transtorno mental (BRASIL, 2014).

Os avanços alcançados na legislação e assistência aos portadores de transtornos mentais, não inseridos na Reforma Psiquiátrica Brasileira, contraditoriamente, mostra o retrocesso do país para a temática do direito à saúde do 'louco infrator'. A medida de segurança ainda é um tema pouco difundido, já que os hospitais de custódia ainda não estão inseridos no SUS. Não obstante o vislumbre da legislação brasileira, tem-se o que de fato se observa no Censo de 2011 com os HCTP ainda em funcionamento. A intersetorialidade da atenção à saúde prisional ainda é um fator engessado no sistema penitenciário brasileiro. O credenciamento dos HCTP ao SUS traz a garantia aos internos da medida de segurança de acesso às terapias que gerem possibilidade de avanço na qualidade da saúde mental, e ainda que valorizem o indivíduo portador de transtorno mental (DINIZ, 2013).

A aplicação da legislação não é efetiva e aumenta a descrença desses indivíduos para um retorno à vida comum. Grandes avanços foram obtidos neste campo: a política nacional, atenção integral ao doente mental, acompanhamento da medida de segurança, a rede de atenção psicossocial, a prevenção de danos e promoção da saúde. Delineiam-se, assim, os consentimentos plausíveis sobre a complexidade do tema. Evidente que há uma relação com os grandes problemas da sociedade atual. Entretanto, por mais simples que seja a execução da internação para a medida de segurança, no plano prático são encontradas dificuldades enormes, alarmantes e diversas vezes impraticáveis. Já que a falta de estabelecimentos adequados e vagas destinadas ao cumprimento é praticamente absoluta (MARCÃO, 2008). 


\section{Conclusões}

O direito à saúde dos inimputáveis é um tema de grande relevância, tanto no campo do Direito quanto no da Saúde. O direito à saúde mental é pouco normatizado na legislação brasileira. A produção legislativa acerca dos direitos, assim como o direito à saúde do portador de transtorno mental que cometeu delito nos anos abordados, trouxe avanços na temática da medida de segurança. O sistema de saúde mental brasileiro é inovador, mas ainda é necessário avançar mais. Particularmente, porque há discordância entre o texto da legislação e seu funcionamento para os doentes mentais. A centralidade do sistema vigente está no cuidar da população, a implementação e efetivação de suas vertentes ainda está a vigorar.

O fortalecimento da rede de atenção psicossocial e da capacitação dos profissionais e da justiça para o redirecionamento da assistência ao louco infrator é desafiador no campo do Direito Sanitário. Entretanto, na atualidade do direito brasileiro, no que tange aos doentes mentais, é controverso internar uma pessoa por meio de ordem judicial e considerar esse ato como método terapêutico. Ainda mais afirmar que essa atitude é eficiente e eficaz no âmbito clínico.

A partir dessa leitura, é notável a necessidade de discutir o direito à saúde dos portadores de doença mental que cometeram delito, além da correta capacitação e treinamento dos profissionais de saúde, visando promover uma atenção integral às pessoas com transtornos mentais. Com a coleta de documentos acerca do assunto, evidencia-se que são necessárias avaliações mais precisas e desvinculações da questão da moralidade no país. Em destaque, estão as normativas que abarcam diretamente os portadores de transtorno mental, que não devem ser tratados como delinquentes. Mas, mediante políticas de saúde, devem tratados como usuários do SUS. O portador de transtorno mental que cometeu algum tipo de delito é inimputável, e o cuidado deve ser integral e igualitário no sistema de saúde.

Por fim, há uma limitação do estudo quanto à ausência de leis diretamente relacionadas aos doentes mentais e a dificuldade nos achados dos portais de legislação. Por se tratar de um tema novo e de relevância considerável no âmbito do direito sanitário, direito penal, e direito dos doentes mentais, deve ser mais abordado e questionado. 


\section{Referências Bibliográficas}

BERTOLOTE, J. M. Legislação relativa à saúde mental: revisão de algumas experiências internacionais. Rev. Saúde Pública, Rio de Janeiro, v.29, n.2, p.152-156, 1995. Disponível em:http:/www.scielo.br/scielo.php?script=sci arttext\&pid=S003489101995000200013\&lg= \&nrm=iso. Acesso em: 15 set. 2014.

BITENCOURT, C.R. Tratado de Direito Penal - Parte Geral. São Paulo: Saraiva, 2004. 807 p.

BRASIL. Presidência da República. Decreto-lei ํo 2.848 de 7 de dezembro de 1940. Código Penal Brasileiro. Diário Oficial da República Federativa do Brasil, Brasília, DF, 31 dez. 1940. Disponível em: http://www.planalto.gov.br/ccivil 03/decretolei/del2848compilado.htm. Acesso em: 28 set. 2014.

BRASIL. Presidência da República. Lei no 7.210, de 11 de julho de 1984. Institui a Lei de Execução Penal. Diário Oficial da União; Brasília, DF, 13 jul. 1984. Disponível em: http://www.planalto.gov.br/ccivil 03/leis/l7210.htm. Acesso em: 07 nov. 2014.

BRASIL. Constituição da República Federativa do Brasil (1988). Brasília: Senado Federal. Disponível em: http://www.planalto.gov.br/ccivil 03/constituicaocompilado.htm. Acesso em: 05 set. 2014.

BRASIL. Presidência da República. Lei no 8.080, de 19 de setembro de 1990. Dispõe sobre as condições para a promoção, proteção e recuperação da saúde, a organização e o funcionamento dos serviços correspondentes e dá outras providências. (Lei Orgânica da Saúde). Diário Oficial da República Federativa do Brasil, Brasília, DF, 20 set. 1990. Disponível em: http://www.planalto.gov.br/ccivil 03/Leis/L8080.htm. Acesso em: 15 abr. 2010.

BRASIL. Conselho Nacional de Política Criminal e Penitenciária. Resolução no 14 de 11 de novembro de 1994. Resolve fixar Regras Mínimas para o Tratamento do Preso no Brasil. Diário Oficial da União, 2 dez. 1994. Disponível em: http://www.criminal.mppr.mp.br/arquivos/File/ExecucaoPenal/Outros/1994resolu14CNPCP. pdf. Acesso em: 10 out. 2014.

BRASIL. Presidência da República. Lei n 10.216, de 6 de abril de 2001. Dispõe sobre a proteção e os direitos das pessoas portadoras de transtornos mentais e redireciona 0 modelo assistencial em saúde mental. Diário Oficial da União, 9 abr. 2001. Disponível em: http://www.planalto.gov.br/ccivil 03/leis/leis 2001/l10216.htm. Acesso em: 10 out. 2014.

BRASIL. Ministério da Saúde. Secretaria de Atenção à Saúde. Legislação em Saúde Mental - 2004 a 2010. Edição XII Colegiado de Coordenadores de Saúde Mental. Brasília, 2010, 257 p. Disponível em: http://www.saude.pr.gov.br/arquivos/File/Legislacao em saude mental 2004 a 2010.pdf. Acesso em: 10 ago. 2014. 
BRASIL. Ministério Público Federal. Procuradoria Federal dos Direitos do Cidadão. Parecer sobre medidas de segurança e hospitais de custódia e tratamento psiquiátrico sob a perspectiva da lei no 10.216/2001. Brasília, DF, 104p. 12 maio 2011a. Disponível em: http://pfdc.pgr.mpf.mp.br/temas-de-atuacao/saude-mental/docs publicacoes/parecer medidas seguranca web.pdf. Acesso em: 20 ago. 2014.

BRASIL. Presidência da República. Decreto no 7.508, de 28 de junho de 2011. Regulamenta a Lei oㅡ 8.080, de 19 de setembro de 1990, para dispor sobre a organização do Sistema Único de Saúde - SUS, o planejamento da saúde, a assistência à saúde e a articulação interfederativa, e dá outras providências. Diário Oficial da União, Brasília, DF, 29 jun. 2011b. Disponível em: http://www.planalto.gov.br/ccivil 03/ ato20112014/2011/decreto/D7508.htm. Acesso em: 12 out. 2014.

BRASIL. Ministério da Saúde. Portaria MS/GM no 3.088, de 23 de dezembro de 2011. Institui a Rede de Atenção Psicossocial para pessoas com sofrimento ou transtorno mental e com necessidades decorrentes do uso de crack, álcool e outras drogas, no âmbito do Sistema Único de Saúde (SUS). Diário Oficial da União, Brasília, DF, 26 dez. 2011c. Disponível

em: http://bvsms.saude.gov.br/bvs/saudelegis/gm/2011/prt3088 23122011 rep.html. Acesso em: 13 out. 2014 .

BRASIL. Ministério da Saúde. Portaria MS/GM no 121, de 25 de janeiro de 2012. Institui a Unidade de Acolhimento para pessoas com necessidades decorrentes do uso de Crack, Álcool e Outras Drogas (Unidade de Acolhimento), no componente de atenção residencial de caráter transitório da Rede de Atenção Psicossocial. Diário Oficial da União, Brasília, DF, 25 jan. 2012a. Disponível em: http://bvsms.saude.gov.br/bvs/saudelegis/gm/2012/prt0121 2501 2012.html. Acesso em: 12 ago. 2014.

BRASIL. Ministério da Saúde. Portaria MS/GM no 148, de 31 de janeiro de 2012. Define as normas de funcionamento e habilitação do Serviço Hospitalar de Referência para atenção a pessoas com sofrimento ou transtorno mental e com necessidades de saúde decorrentes do uso de álcool, crack e outras drogas, do Componente Hospitalar da Rede de Atenção Psicossocial, e institui incentivos financeiros de investimento e de custeio. Diário Oficial da União, Brasília, DF, 31 jan. 2012b. Disponível em: http://bvsms.saude.gov.br/bvs/saudelegis/gm/2012/prt0148 3101 2012.html. Acesso em: 12 ago. 2014.

BRASIL. Ministério da Saúde. Portaria MS/GM no 349, de 29 de fevereiro de 2012. Altera e acresce dispositivo à Portaria $n^{\circ} 148 / G M / M S$, de 31 de janeiro de 2012, que define as normas de funcionamento e habilitação do Serviço Hospitalar de Referência para atenção a pessoas com sofrimento ou transtorno mental e com necessidades decorrentes do uso de crack, álcool e outras drogas, do Componente Hospitalar da Rede de Atenção Psicossocial e institui incentivos financeiros de investimento e de custeio. Diário Oficial da União, Brasília, DF, 29 fev. 2012c. Disponível em: http://bvsms.saude.gov.br/bvs/saudelegis/gm/2012/prt0349 2902 2012.html. Acesso em: 12 ago. 2014. 
BRASIL. Ministério da Saúde. Portaria MS/GM no 854, de 22 de agosto de 2012. Altera a Tabela de Procedimentos, Medicamentos, Órteses, Próteses e Materiais Especiais do Sistema Único de Saúde os seguintes atributos dos procedimentos a seguir especificados, a partir da competência Outubro de 2012. Diário Oficial da União, Brasília, DF, 22 ago. 2012d. http://bvsms.saude.gov.br/bvs/saudelegis/sas/2012/prt0854 2208 2012.html. Acesso em: 12 ago. 2014.

BRASIL. Portaria MS/GM o 855 de 22, de agosto de 2012. Altera a Tabela de Procedimentos, Medicamentos, Órteses, Próteses e Materiais Especiais do Sistema Único de Saúde os seguintes atributos dos procedimentos a seguir especificados, a partir da competência Outubro de 2012. Diário Oficial da União, Brasília, DF, 22 ago. 2012e. Disponível em: http://bvsms.saude.gov.br/bvs/saudelegis/sas/2012/prt0855 2208 2012.html. Acesso em: 12 ago. 2014.

BRASIL. Ministério da Saúde. Portaria MS/GM no 856, de 22 de agosto de 2012. Definir mecanismos para operacionalização dos procedimentos específicos para a atenção residencial de caráter transitória às pessoas com necessidades decorrentes do uso de álcool, crack e outras drogas, realizados em serviços de atenção em regime residencial. Diário Oficial da União, Brasília, DF, 22 ago. 2012f. Disponível em: http://bvsms.saude.gov.br/bvs/saudelegis/sas/2012/prt0856 2208 2012.html. Acesso em: 12 ago. 2014.

BRASIL. Presidência da República. Lei ㄲo 12.714 de 14 de novembro de 2012. Dispõe sobre o sistema de acompanhamento da execução das penas, da prisão cautelar e da medida de segurança. Diário Oficial da União, Brasília, DF, 14 nov. 2012g. Disponível em: http://www.planalto.gov.br/ccivil 03/ Ato2011-2014/2012/Lei/L12714.htm. Acesso em: 12 ago. 2014.

BRASIL. Ministério da Saúde. Portaria MS/GM o 1.218, de 26 de outubro de 2012. Altera a redação da Portaria no 854/SAS/MS, de 22 de agosto de 2012. Diário Oficial da União, Brasília, DF, 26 out. 2012h. Disponível em: http://bvsms.saude.gov.br/bvs/saudelegis/sas/2012/prt1218 2610 2012.html. Acesso em: 12 ago. 2014.

BRASIL. Ministério da Saúde. Ministério da Justiça. Portaria Interministerial oํ 1, de 2 de janeiro de 2014. Institui a Política Nacional de Atenção Integral à Saúde das Pessoas Privadas de Liberdade no Sistema Prisional (PNAISP) no âmbito do Sistema Único de Saúde (SUS). Diário Oficial da União, Brasília, DF, 02 jan. 2014a. Disponível em: http://bvsms.saude.gov.br/bvs/saudelegis/gm/2014/pri0001 0201 2014.html. Acesso em: 10 ago. 2014. 
BRASIL. Portaria MS/GM no 94, de 14 de janeiro de 2014. Institui o serviço de avaliação e acompanhamento de medidas terapêuticas aplicáveis à pessoa com transtorno mental em conflito com a Lei, no âmbito do Sistema Único de Saúde (SUS). Diário Oficial da União, Brasília, DF, 14 jan. 2014b. Disponível em: http://bvsms.saude.gov.br/bvs/saudelegis/gm/2014/prt0094 1401 2014.html

Acesso em: 12 ago. 2014.

BRASIL. Ministério da Saúde. Portaria GM/MS no 482, de 14 de janeiro de 2014, institui o serviço de avaliação e acompanhamento de medidas terapêuticas aplicáveis à pessoa com transtorno mental em conflito com a Lei, no âmbito do Sistema Único de Saúde (SUS). Diário Oficial da União, Brasília, DF, 14 jan. 2014c. Disponível em: http://bvsms.saude.gov.br/bvs/saudelegis/gm/2014/prt0482 0104 2014.html. Acesso em: 12 ago. 2014.

COHEN, C. A periculosidade social e a saúde mental. Rev. Bras. Psiquiatr. São Paulo, v. 21, n.4, p.197-198, $1999 . \quad$ Disponível em: http://www.scielo.br/scielo.php?script=sci arttext\&pid=S151644461999000400006\&lng=pt\& nrm=iso\&tlng=pt. . Acesso em: 20 set. 2014.

CONSELHO REGIONAL DE MEDICINA DO ESTADO DE SÃO PAULO (CREMESP). Medida de segurança - uma questão de saúde e ética. (Org.) CORDEIRO, Q. e LIMA, M.G. A de. São Paulo: CREMESP, 2013. 256 p.

CORREIA, L.C.; LIMA, I. M. S. O. e ALVES, V. S. Direitos das pessoas com transtorno mental autoras de delitos. Cad. Saúde Pública, Rio de Janeiro, v.23, n.29, p.1995-2002, 2007. Disponível em: http://www.scielo.br/pdf/csp/v23n9/02.pdf. Acesso em: 11 out. 2014.

DINIZ, D. A custódia e o tratamento psiquiátrico no Brasil: censo 2011. Brasília: Universidade de Brasília, 2013. 382 p.

FALCONI, R. Sistema presidial: reinserção social? São Paulo: Ícone, 1998. 271p.

GRECO, R. Curso de Direito Penal. Rio de Janeiro: Impetus, 2007. 816p.

JACOBINA, P. V. Direito penal da loucura: Medida de segurança e reforma psiquiátrica. Brasília: ESMPU, 2008. 152p.

MALCHER, F. S. A questão da inimputabilidade por doença mental e a aplicação das medidas de segurança no ordenamento jurídico atual. Jus Navigandi. Teresina, v.14, n. 2104, 5 abr. 2009. Disponível em: http://jus.com.br/artigos/12564. Acesso em: 15 set. 2014.

MARCÃO, R. Curso de Execução Penal. São Paulo: Saraiva, 2008. 314p.

MATEUS, M. D. (org.). Políticas de saúde mental: baseado no curso Políticas Públicas de Saúde Mental do CAPS. São Paulo: Instituto de Saúde, 2013. 400 p. 
VAZ, P. J. P. As medidas de segurança e os direitos humanos dos inimputáveis. Jus Navigandi. Teresina, v.17, n.3264, 2012. Disponível em: http://jus.com.br/artigos/21956 Acesso em: 15 set. 2014.

Recebido para publicação em 22 de janeiro de 2015. Admitido para publicação em 27 de abril de 2015. 